\title{
Optimum treatment of end-stage renal failure
}

During the last 10 years renal dialysis and the use of transplants in children have passed from the experimental to the routine: a development which has occurred within highly specialised units, isolated from general paediatrics. It is therefore not surprising that parents and children often have little idea of what life on dialysis or after a transplant is like. Information from the media tends to be highly misleading in its dramatisation of the life-saving nature of dialysis and the lack of adequate facilities for treatment in the UK, while the very real stresses of life on dialysis are ignored. The inadequate provision of dialysis is real enough, particularly for adults aged over 50 , and the total number of patients per million population treated in the UK is less than half the number in the USA and Japan. However, the recommendations of the two reports of the British Association for Paediatric Nephrology ${ }^{12}$ have largely been accepted and followed by the DHSS so that in 19804.7 children per million at risk were accepted for treatment. ${ }^{3}$ This number was among the highest in Europe and represents about three-quarters of the incidence of chronic renal failure in childhood. Given the small number of paediatric dialysis unit beds, this high acceptance rate can be maintained only by treating most children for no longer than a few months in hospital before they leave to dialyse at home or to receive a renal transplant.

\section{Timing and choice of treatment}

Nothing is gained by struggling on with conservative management until the child is weak and ill from malnutrition or admitted in extremis with pulmonary oedema. Dialysis should therefore be started when the glomerular filtration rate has fallen to 6-7 $\mathrm{ml} / \mathrm{min}$ per $1.73 \mathrm{~m}^{2}$.

The choice of treatment rests between the active options of (1) haemodialysis, (2) peritoneal dialysis, and (3) renal transplant, and (4) the passive option of allowing the child to die of renal failure. The decision is rarely straightforward and the child and his family should become acquainted with the paediatric nephrologist who will be responsible for dialysis together with the supporting team of dialysis nurses, child psychiatrist, social worker, school teacher, and dietitian at least 6 and preferably 12 months before the time for dialysis is reached. Advance warning of this stage can be gained by plotting serial estimates of glomerular filtration rate from height and plasma creatinine levels ${ }^{4}$ on semilogarithmic graph paper. Of the 38 children treated in the West Midlands regional children's dialysis unit since it opened 3 years ago, $13(30 \%)$ presented with life-threatening complications of renal failure requiring immediate dialysis. Previously unsuspected renal disease made this potential disaster unavoidable in 7 children but the remaining 6 were known to have renal failure and were being followed up by paediatricians who had failed to take account of the rate at which renal function was deteriorating.

\section{Peritoneal dialysis}

Using the Tenckhoff silastic peritoneal catheter, prolonged survival is possible with intermittent (IPD), continuous ambulatory (CAPD), or continuous cyclic (CCPD) peritoneal dialysis. Because of the length of time the patient spends attached to the machine, IPD is not widely favoured. The newer technique of CAPD was first described in 1976 but already appears well suited to the needs of children. ${ }^{5}$ In a recent review the 3-year survival of adult patients on CAPD was $77 \%$ but within the first year $20 \%$ had changed to another treatment. ${ }^{6}$ A review of 43 European children shows that $35 \%$ abandoned CAPD in the first year, generally because of peritonitis ${ }^{3}$ which tends to recur frequently in a few patients whose personality, lifestyle, or susceptibility to infection makes them unsuited to CAPD. The advantages of CAPD are its technical simplicity which permits training for home dialysis in less than 2 weeks, the continuous biochemical control which lessens the need for dietary and fluid restriction and reduces anaemia, the low capital cost, and the portability of equipment which facilitates trips away from home and the dialysis unit. We consider it the treatment of choice for children weighing less than $15 \mathrm{~kg}$ and for diabetic children in whom insulin can be administered in the dialysis fluid. We allow the older children to make their own choice after visiting the dialysis unit. Nearly half our patients have started on CAPD $(5 / 15$ in $1980,5 / 9$ in 1981 , and $7 / 14$ in 1982) but of the 17 patients 1 died of infection, 5 had to change to haemodialysis because of infection, 4 received successful renal transplants, and the remainder continue treatment after 1 month to $2 \frac{1}{2}$ years.

This experience underlines the absolute necessity for haemodialysis facilities to support the CAPD programme. Although IPD and the newer technique 
of CCPD require costly machinery, the popularity of CCPD is likely to increase if it proves to have genuinely lower infection rates.

\section{Haemodialysis}

With 3-year survival rate exceeding $90 \%$ in children treated at home and $80 \%$ for hospital treatment, haemodialysis is firmly established as the yardstick by which the success of any newer method of dialysis must be measured. ${ }^{3}$ Treatment entails access to a vessel with high blood flow and attachment to a machine for 3-6 hours, three times a week. Episodes of hypotension with nausea or vomiting and muscle cramps are common during dialysis particularly in smaller children weighing less than $20 \mathrm{~kg}$ in whom vascular access may also cause problems. During treatment most children can sit in recliner chairs reading, writing, playing games, or even cooking, so there should be little interruption to schooling by hospital dialysis. Vascular access by silastic shunts is painless but the life of such shunts is limited by clotting or infection, they are unsightly, and there is a limit to the number of vessels in which they can be placed. The arteriovenous fistula provides more durable access but the injection of local analgesic is painful and the insertion of needles for dialysis often causes great anxiety both to children and parents during training for home dialysis. The complexity of haemodialysis equipment is daunting for most families who need at least 3 and often longer than 6 months to train for home treatment. Despite the difficulties, about half our patients have opted for the proved survival rates and the intermittent nature of haemodialysis.

\section{Transplantation}

There can be no doubt that a successful renal transplant is the ideal treatment for chronic renal failure in children, fully justifying the increased risk of death from infection. ${ }^{7}$ The operation to place the new kidney extraperitoneally in the iliac fossa is fairly straightforward and most childien can leave hospital within 3 weeks. In the first 3 months the child will remain away from school because the risk of acute rejection is great and the dose of immunosuppressants high. Thereafter, if renal function is normal, the patient can return to a virtually normal life in full-time education with normal prospects for employment and family life as an adult.

Both patient survival $(92 \%$ versus $85 \%$ at 1 year) and survival of the first cadaver graft (69\% versus $57 \%$ at 1 year) are significantly improved in children who are transplanted in centres with full paediatric facilities $^{8}$ but more than half the children in Europe still receive their transplants in adult units. The continuing improvements in the preparation of transplant recipients and the use of immunosuppressant drugs means that more than $70 \%$ of children receiving their first cadaver graft can now expect it to be functioning after 6 years and many for a good while longer. Recent advances have come from improved control of fluid balance during the perioperative period in very young children, ${ }^{9}$ from the use of donor-specific blood transfusion to identify suitable living related kidney donors, ${ }^{10}$ and potentially from the use of cyclosporin $A$ as an immunosuppressant instead of corticosteroids and azathioprine. ${ }^{11}$

Even if a renal transplant is successful it is unlikely that the recipient will ever be free from daily drugs to prevent rejection, from occasional hospital visits and blood tests to detect rejection, and from worry about chronic rejection for which there is yet no effective treatment.

\section{Quality of life}

Up to $5 \%$ of children who enter a dialysis and transplant programme will spend their entire lives on dialysis apart from 3 or 4 unsuccessful attempts to give them a transplant. Unfortunately life on dialysis is far from easy in several respects and for some children the best choice will be for no active treatment.

Diet. The struggle to persuade anorexic children on dialysis to eat sufficient calories and protein while denying them their favourite crisps and high potassium foods often gives way to a struggle after transplantation to limit calorie intake when steroid treatment has generated a voracious appetite.

Fluids. The need for restriction to twice the insensible loss $\left(600 \mathrm{ml} / \mathrm{m}^{2}\right.$ per day) plus urine output is easily the most distressing aspect of dialysis treatment for most families. Inability to comply with the fluid restriction has led to death from pulmonary oedema of one patient, and has led to near deaths in $\mathbf{3}$ of $\mathbf{3 8}$ children.

Drugs. At the very least drugs to prevent bone disease on dialysis and to prevent rejection after transplantation will serve to remind the child that he is a patient and interfere with his emotional development.

Growth. Very few children on haemodialysis grow normally although bone maturation is delayed and final height is not reached until the early twenties. CAPD may allow a proportion of children to grow normally but there is insufficient evidence yet from 
patients treated for longer than one year. After transplantation, reduction of the daily prednisolone dose to $0.3 \mathrm{mg} / \mathrm{kg}$ or less permits catch-up growth in prepubertal children with good renal function but after puberty growth is poor even though the bone age is usually retarded.

School attendance. Suprisingly, the majority of children performed badly at school for at least a year before they started dialysis, even if the renal failure was undiagnosed. Although home dialysis and transplant permit full-time education there is a continuing need for supervision and encouragement by the school teacher attached to the dialysis unit to help the child achieve his full educational potential.

Sporting activities. Children on haemodialysis maintain a haemoglobin concentration of $6-7 \mathrm{~g} / \mathrm{dl}$ and those on CAPD 7-10 g/dl so many have impaired exercise tolerance.

Self-image. A number of factors combine to make it very difficult for a child on dialysis to develop a normal self-image. At least half become isolated at school, losing contact with friends and having difficulty in making new ones. Much effort is needed from the staff of the children's dialysis unit to promote emotional growth and development.

Knowledge of these problems helps some parents to accept medical advice not to dialyse their child. This advice is indicated for children with mental handicaps severe enough to prevent them from having any prospect of understanding and accepting dialysis, for children with very severe physical handicap such as paraplegia due to spina bifida (we have treated 2 children with spina bifida who were mobile with crutches and able to attend normal schools), for children affected by other progressive and lethal diseases (for example muscular dystrophy or malignancy), and for children who are seriously emotionally disturbed by hospital visits and repeated venepunctures. Experience with dialysing and transplanting very young children under age 4 years is limited to a few centres ${ }^{8}$ with full paediatric facilities. Transplantation of such children should not be attempted in adult units because of the very high rate of primary graft failure which is associated with lack of paediatric medical and nursing expertise.

Two firm conclusions can be drawn. Firstly, in
1983 there is no acceptable reason for a medically fit 5 -year-old or older child in the UK to be denied treatment in a paediatric dialysis and transplant programme. Secondly, this happy state of affairs can only be maintained as the number of successfully treated children increases if further development of existing paediatric dialysis units described in the British Association for Paediatric Nephrology reports ${ }^{12}$ continues.

\section{References}

1 Chantler C, Houston I B, White R H R. Future care for children with chronic renal failure in the United Kingdom. Report for the British Association for Paediatric Nephrology, 1974: 1-12.

2 Houston I B, Barratt T M, Chantler C, White R H R. Siting of units to care for children with chronic renal failure in the United Kingdom. A progress report 1974/1979. A report by the British Association for Paediatric Nephrology, 1979: 1-12.

3 Broyer M, Donckerwolcke $\mathrm{R}$ A, Brunner F P, et al. Combined report on regular dialysis and transplantation of children in Europe, 1980. Proc Eur Dial Transplant Assoc 1981; 18: 60-87.

4 Morris M C, Allanby C W, Toseland P, Haycock G B, Chantler C. Evaluation of a height/plasma creatinine formula in the measurement of glomerular filtration rate. Arch Dis Child 1982; 57: 611-5.

5 Eastham E J, Kirpalani H, Francis D, Gokal R, Jackson R H. Paediatric continuous ambulatory peritoneal dialysis. Arch Dis Child 1982; 57: 677-80.

6 Oreopoulos D G, Khanna R, Williams P, Vas S I Continuous ambulatory peritoneal dialysis-1981. Nephron 1982; 30: 293-303.

7 Chantler C, Carter J E, Bewick M, et al. 10 years' experience with regular haemodialysis and renal transplantation. Arch Dis Child 1980; 55: 435-45.

8 Chantler C, Donckerwolcke R A, Brunner F P, et al. Combined report on regular dialysis and transplantation of children in Europe, 1978. Proc Eur Dial Transplant Assoc 1979; 16: 74-104.

9 Anonymous. Renal transplantation in very young children. Lancet 1982 ; ii: $367-8$.

10 Anonymous. Living related kidney donors. Lancet 1982; ii: 696.

11 Starzl T E, Iwatsuki S, Malatack J J, et al. Liver and kidney transplantation in children receiving cyclosporin $\mathrm{A}$ and steroids. J Pediatr 1982; 100: 681-6.

M H WINTERBORN

West Midlands Regional Children's Dialysis Unit, East Birmingham Hospital, Bordesley Green East, Birmingham B9 5ST 